\title{
DIFFERENCES IN ABSORPTION OF THE VARIOUS FATTY ACIDS STUDIED IN CHILDREN WITH STEATORRHEA
}

\author{
By J. FERNANDES, J. H. van de KAMER and H. A. WEIJERS
}

(From the Central Institute for Nutrition and Food Research TNO, Utrecht, The Netherlands)

(Received for publication September 20,1960; accepted September 11, 1961)

In studies in animals it has been shown (1) that the chain length of a fatty acid is related to the extent of its absorption; i.e., the greater the molecular weight, the less the degree of absorption. It has been our purpose to find whether this relationship is true also in patients with steatorrhea. We have studied the absorption of various fatty acids, fed as triglycerides, in patients who have disturbed fat absorption due to celiac disease, cystic fibrosis of the pancreas, and ileectomy. The steatorrhea in each of these categories is based on distinctly different defects. In celiac disease the poor fat absorption is caused by. dysfunction of the mucosal cells (2), but in cystic fibrosis the steator- rhea reflects diminished lipolysis due to deficiency of pancreatic lipase. In the third instance-operative shortening of the intestine-there is obviously a reduction of mucosal surface available for absorption.

Also it has been our purpose to determine whether the absorption of a given fatty acid is influenced by simultaneously feeding other fatty acids. This may have therapeutic implications in that it could afford a guide to the choice of dietary fats for patients with steatorrhea.

Various experimental designs have been used in the past for studying the process of fat absorption. Some investigations, in both animal experi-

TABLE I

Composition of fat mixtures used in the different experiments

\begin{tabular}{|c|c|c|c|c|c|c|c|c|c|c|c|c|}
\hline \multirow[b]{2}{*}{ Fat and fat mixtures } & \multicolumn{12}{|c|}{ Fatty acids* $(\%) \dagger$} \\
\hline & $4: 0$ & $6: 0$ & $8: 0$ & $10: 0$ & $12: 0$ & $14: 0$ & $16: 0$ & $18: 0$ & $18: 1$ & $18: 2$ & $18: 3$ & $22: 1$ \\
\hline A. Butterfat & & 7 & & 5 & 6 & 11 & 24 & 13 & 30 & & & \\
\hline $\begin{array}{l}\text { B. Olive oil esterified with } \\
\text { caprylic acid mixed with } \\
\text { coconut oil }\end{array}$ & & & 23 & 4 & 24 & 12 & 9 & 3 & 23 & & & \\
\hline $\begin{array}{l}\text { C. Coconut oil, cocoa butter, } \\
\text { and beef tallow }\end{array}$ & & & 1 & 2 & 20 & 12 & 20 & 20 & 24 & & & \\
\hline $\begin{array}{l}\text { D. Beef tallow, cocoa butter, and } \\
\text { rapeseed oil }\end{array}$ & & & & & & 1 & 16 & 19 & 32 & 7 & 4 & 21 \\
\hline $\begin{array}{l}\text { E. Beef tallow, cocoa butter, and } \\
\text { rapeseed oil; esterified with } \\
\text { trilaurin }\end{array}$ & & & & & 16 & 1 & 21 & 16 & 30 & 2 & & 12 \\
\hline F. Linseed oil and sunflower oil & & & & & & & 6 & 4 & 26 & 32 & 27 & \\
\hline G. Coconut oil and olive oil & & & 4 & 3 & 22 & 7 & 10 & 3 & 46 & & & \\
\hline $\begin{array}{l}\text { H. Coconut oil, hydrogenated } \\
\text { olive oil, and olive oil }\end{array}$ & & & 4 & 3 & 22 & 8 & 9 & 40 & 8 & & & \\
\hline I. Coconut oil & & & 8 & 6 & 47 & 17 & 9 & 3 & 6 & & & \\
\hline K. Coconut oil and rapeseed oil & & & 4 & 3 & 28 & 10 & 6 & 1 & 20 & & & 30 \\
\hline
\end{tabular}

* The number of carbon atoms in the fatty acid is followed by the number of double bonds. Thus, palmitic acid is $16: 0$ and linolenic acid is $18: 3$.

† Only those fatty acids indicated by italics are considered in the experiments. 
ments $(1,3)$ and clinical studies (4-7), have been based on comparisons between dietary fat and fat in the chyle. Such data are somewhat incomplete because fatty acids of lower molecular weight are absorbed into the portal system rather than into the intestinal lymphatics (8).

Other studies have relied upon analysis of the fats in the intestinal contents after administration of natural fats $(9,10)$ or labeled fatty acids $(11)$. This method is limited because it shows fat absorption only at a given moment rather than the net absorption after a fat feeding. Furthermore, the necessary intubation may affect motor and secretory physiology, thus disturbing normal processes of absorption.

The most satisfactory means of studying fat absorption probably is comparison of the fecal fat with the fats in the diet. This method has enabled us to investigate the net absorption of administered fatty acids without altering homeostasis. To be sure, the method is valid only if the contribution of endogenous lipids to fecal fat is relatively small. This has been demonstrated in patients with cystic fibrosis of the pancreas or bile duct atresia by administration of labeled fatty acids. In these instances (12), fats recovered in the feces were chiefly of alimentary origin. In the present investigation we also have found that the contribution of nonalimentary lipids to the fecal fats is small, and we do not distinguish between the endogenous and exogenous sources. The possibility that alteration of fatty acids may occur during passage through the gut was not anticipated in the design of these experiments, but this factor is considered in the discussion of the results.

\section{METHODS}

A. Clinical. Metabolic balance studies were conducted in 8 children with celiac disease, 7 children with cystic fibrosis of the pancreas, and 1 child with steatorrhea after ileectomy. The patients were fed a low fat diet comprised of common food items. The fat under investigation was added to the diet by being mixed into skimmed milk porridge. In successive balance periods the quantity of fat fed to a given patient was kept constant. During the periods when the patients were fed the basic low fat diet, their fat excretion did not exceed $2 \mathrm{~g}$ of fat per day. This is considered to be the amount of lipids excreted from endogenous sources, and in order to minimize the influence of this baseline level on the measured fecal fat excretions, only those balance periods in which over 10 per cent of the administered amount of fat was found in the feces were used as sources of data. The amount of fat administered was as large as possible; thus, the older children received from 60 to $80 \mathrm{~g}$ daily, and the younger were fed $40 \mathrm{~g}$ per day.

The dietary fats were selected and modified so that their composition would permit successive testing of a wide variety of fatty acids. Thus the fats administered (Table I) contain most of the short and long chain and saturated and unsaturated acids found in the diet, as well as some which are not commonly eaten (erucic acid and linolenic acid). It can be seen in Table I that mixtures or modifications of olive, sunflower, linseed, or rapeseed oils were fed for evaluation of the extent of absorption of unsaturated fatty acids. To evaluate the absorption of saturated acids, mixtures or modifications of butterfat, coconut oil, beef fat, cocoa butter, or hydrogenated olive oil were fed.

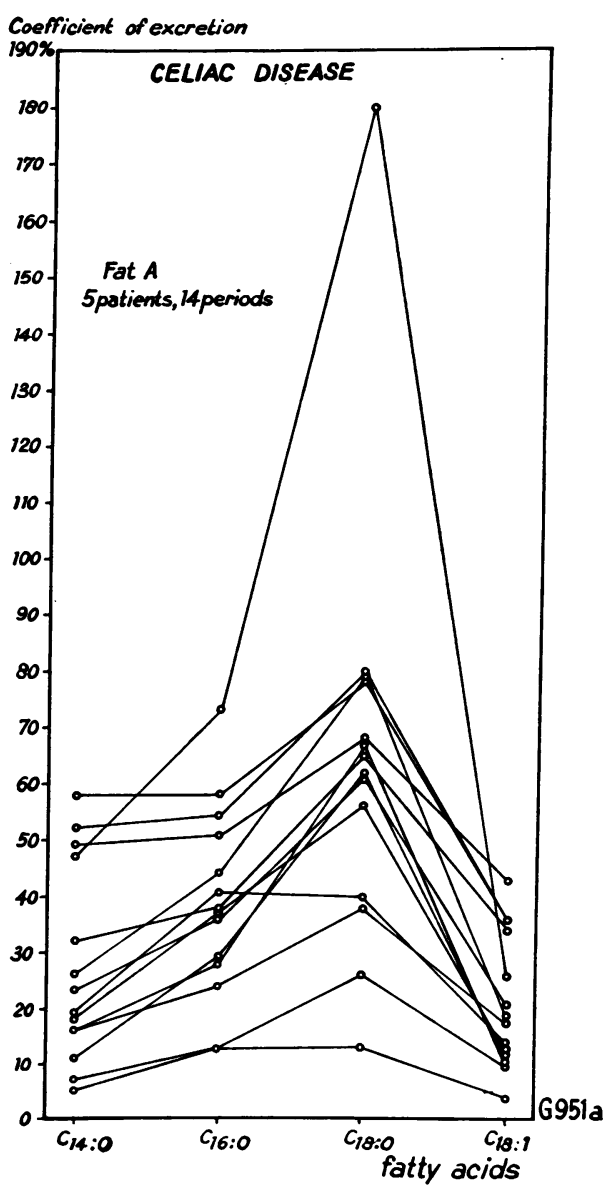

Fig. 1. Coefficients of eXCREtion of the COMPONENT FATTY ACIDS OF BUTTERFAT. These data were obtained in five patients with celiac disease. Each series of points connected by a line represents one balance period. 


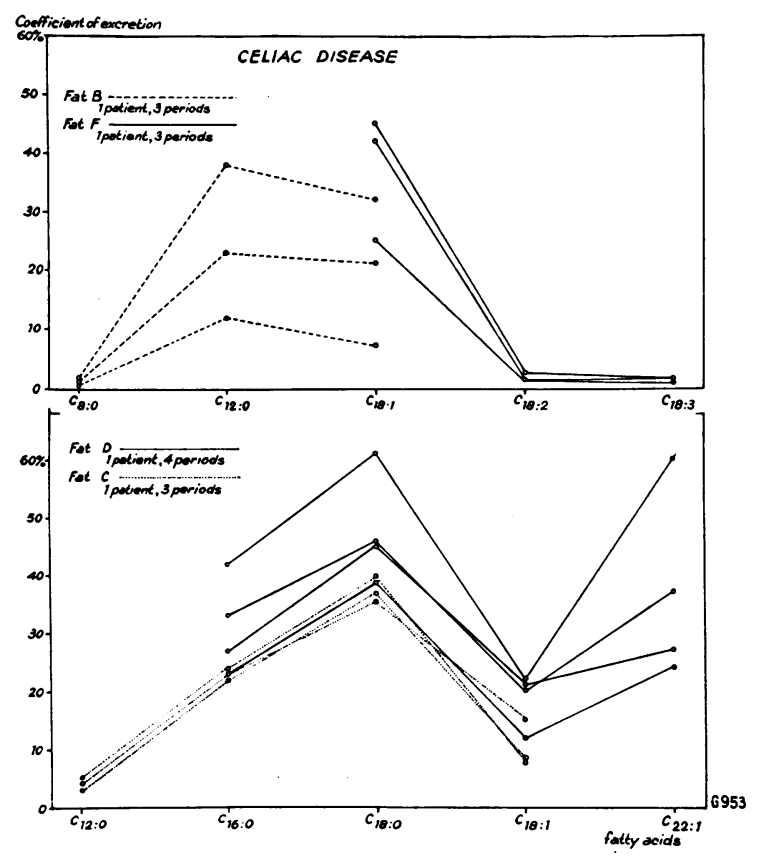

Fig. 2. Coefficients of excretion of SEVERAL Fatty acids in fats Fed to a patient With Celiac disease. Each series of points connected by a line represents one balance period.

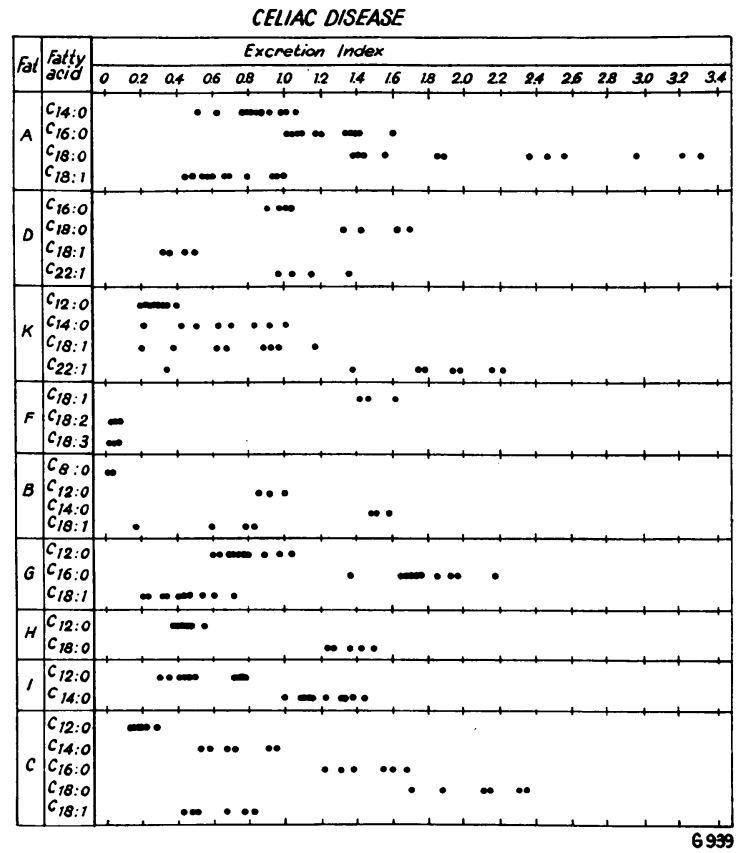

Fig. 3. EXCRETION INDICES OF VARIOUS FATTY ACIDS AFTER ADMINISTRATION OP DIFFERENT FATS TO EIGHT PATIENTS WITH CELIAC DISEASE.
Each balance period, consisting of 2 to 3 days of fat feeding during which the feces were quantitatively collected, was preceded by a priming period of at least 2 days on the same diet. During the balance periods no medications were given to the patients, in order to avoid altering chemical and bacterial factors in the intestine.

$B$. Chemical. In the course of the investigation gasliquid chromatography became available but, initially, fatty acid analyses were carried out by a combination of partition chromatography $(13,14)$ and alkali isomerization (15). In this method titrimetric determinations of the total fatty acids before and after oxidation established the amount of unsaturated acids present in the fat; i.e., unsaturated fatty acids equal total fatty acids (those present before oxidation) minus saturated fatty acids (those present after oxidation).

The amounts of polyunsaturated acids, determined as linoleic and linolenic acids by alkali isomerization, were then deducted from the total unsaturated fatty acids to

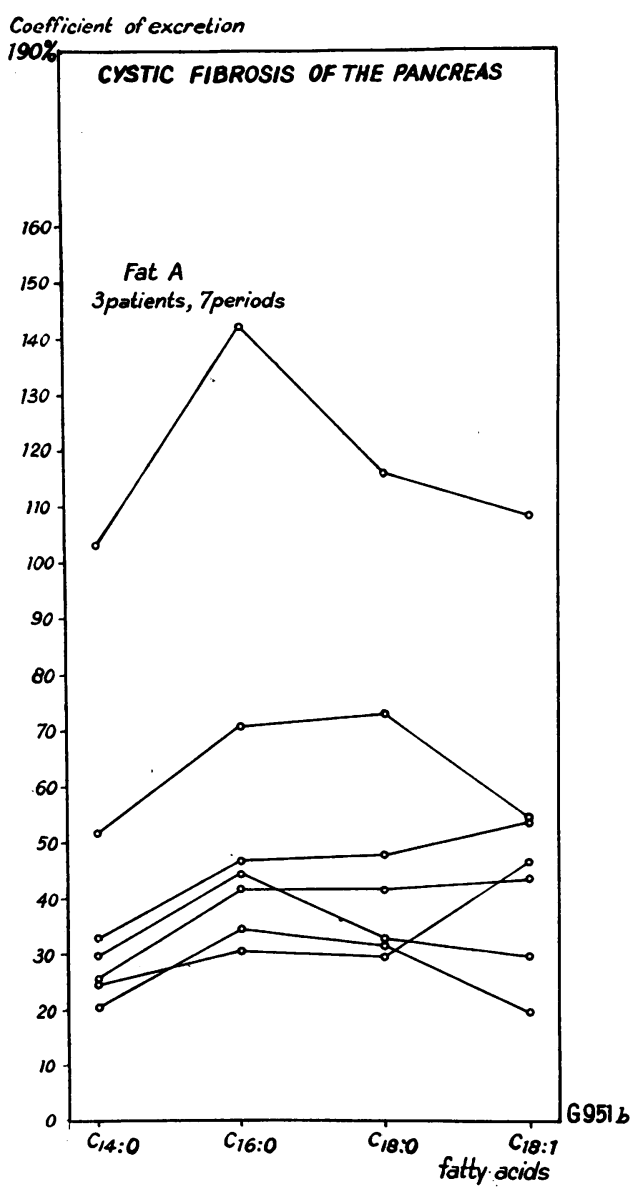

Fig. 4. Coefficients of excretion of the comPONENT FATTY ACIDS OF BUTTERFAT. These data were obtained in three patients with cystic fibrosis of the pancreas. Each series of points connected by a line represents one balance period. 
give the amount of monoenoic acids, expressed as oleic acid: oleic acid equals unsaturated acids minus polyenoic acids.

Replacement of this rather tedious method with gasliquid chromatography (16) yielded comparable results.

The analyses of the dietary fats and the fecal fats permitted calculation of the extent of absorption of each fatty acid. This is expressed as a coefficient of excretion as follows.

Coefficient of excretion of any given fatty acid

$$
=\frac{\text { grams of that fatty acid in feces }}{\text { grams of that fatty acid in diet }} \times 100
$$

RESULTS

A. Celiac disease. When butterfat (fat $\mathrm{A}$, Table I) was fed to five children with celiac disease, the coefficient of excretion (CE) of the $n$-saturated fatty acids rose as the molecular weight increased. The $\mathrm{CE}$ of oleic acid was lower than its saturated homolog (Figure 1). These same rela- tionships were observed in the experimental periods in which the patient's diet contained fatty acids of longer chain length or greater unsaturation than those encountered in butterfat (Figure 2). In these studies it was found that the increase in coefficient of excretion with increase in molecular weight was true for the monoenoic series (Figure 2 , fat $D$ ) as well as the $n$-saturated series (fats $\mathrm{B}, \mathrm{C}, \mathrm{D}$ ). The polyunsaturated fatty acids (fat F) were almost totally absorbed.

It is apparent in Figures 1 and 2 that, between patients and even in the same patient on different occasions, the $\mathrm{CE}$ of a given fatty acid must depend to some extent on the amount of fat not absorbed. In order to eliminate the spread of points shown in the figures and to compare the relative degree of nonabsorption of a particular fatty acid, the excretion can be expressed as a function of the steatorrhea by dividing the $\mathrm{CE}$ of the particular

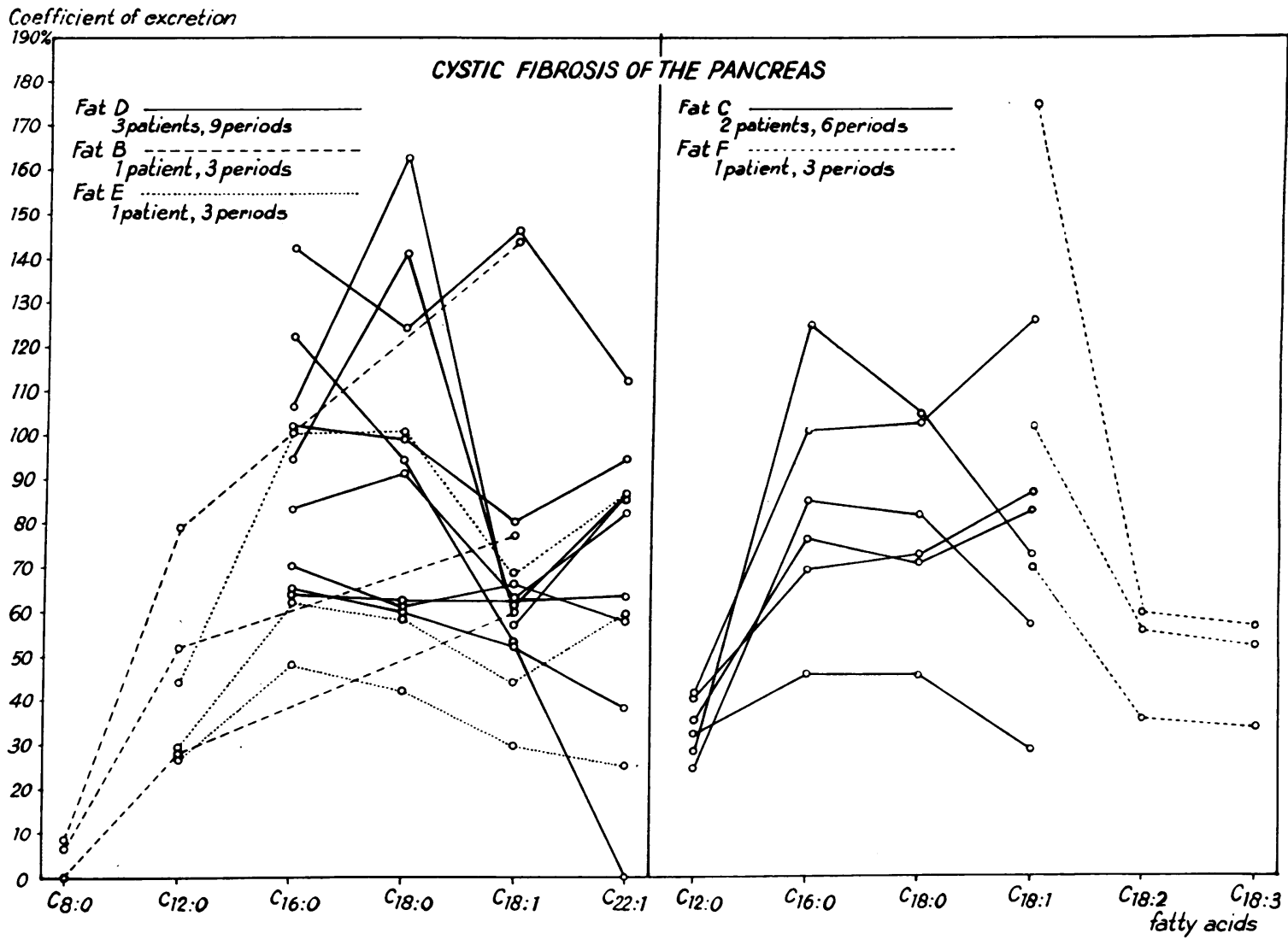

G 954

Fig. 5. COEFFicients OF EXCRETION OF SEVERAL FATTY ACIDS IN FATS FED to SEVEN PATIENTS WITH CYSTIC FIBROSIS of THE PANCREAS. Each series of points connected by a line represents one balance period. 
fatty acid by the CE of all the dietary fat. Thus,

$$
\frac{\mathrm{CE} \text { fatty acid }}{\mathrm{E} \text { total fatty acids }}=\text { excretion index }
$$

The excretion indices of the patients with celiac disease are shown in Figure 3. Again it is apparent that in every case there is a progressive increase in the excretion index of each member of the $n$-saturated series with the increase in molecular weight. Also, the relationship in the excretion of the unsaturated acids is seen again. This method of expressing the extent of excretion shows clearly that any given acid is absorbed to a greater or lesser extent depending on the composition of the fat fed. For example, lauric acid, $\mathrm{C}_{12}$, has a low excretion index if the dietary fat contains mostly larger saturated fatty acids (fat $\mathrm{C}$ ) in addition to the lauric acid, but it has a high excretion index if it is fed in combination with more completely absorbed acids such as caprylic acid, $\mathrm{C}_{8}$, and oleic acid, $\mathrm{C}_{18}$ (fat B). Similarly, oleic acid has a high excretion index if the dietary fat contains, in addition, linoleic and linolenic acids (fat F), but it has a low index when administered in combination with saturated fatty acids which are less well absorbed (fat D).

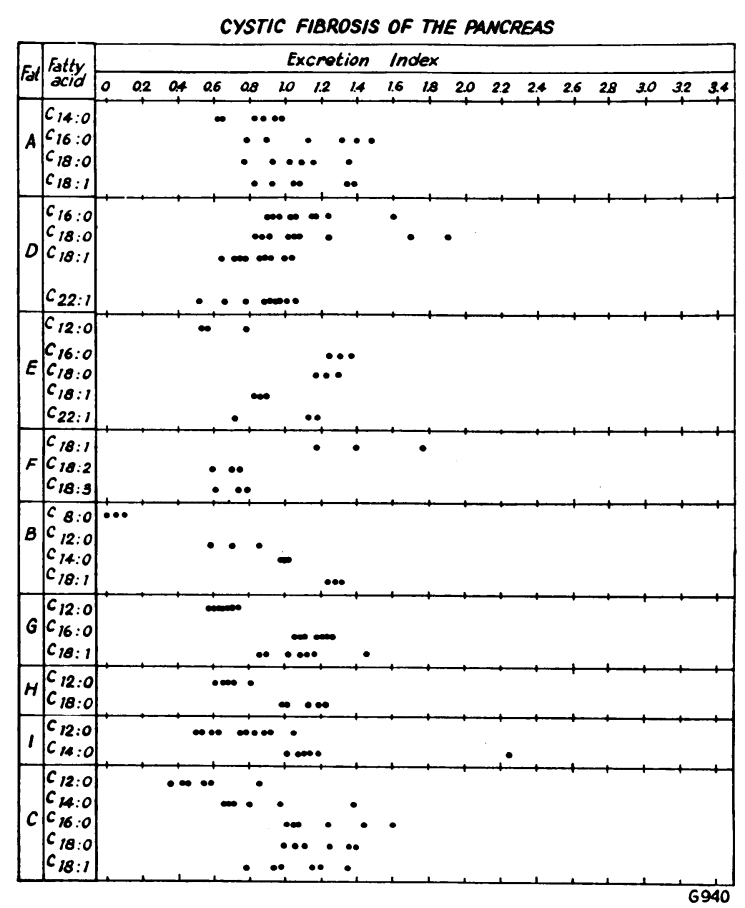

Fig. 6. EXCRETION INDICES OF VARIOUS FATTY ACIDS AFTER ADMINISTRATION OF DIFFERENT FATS TO SEVEN PATIENTS WITH CYSTIC FIBROSIS OF THE PANCREAS.

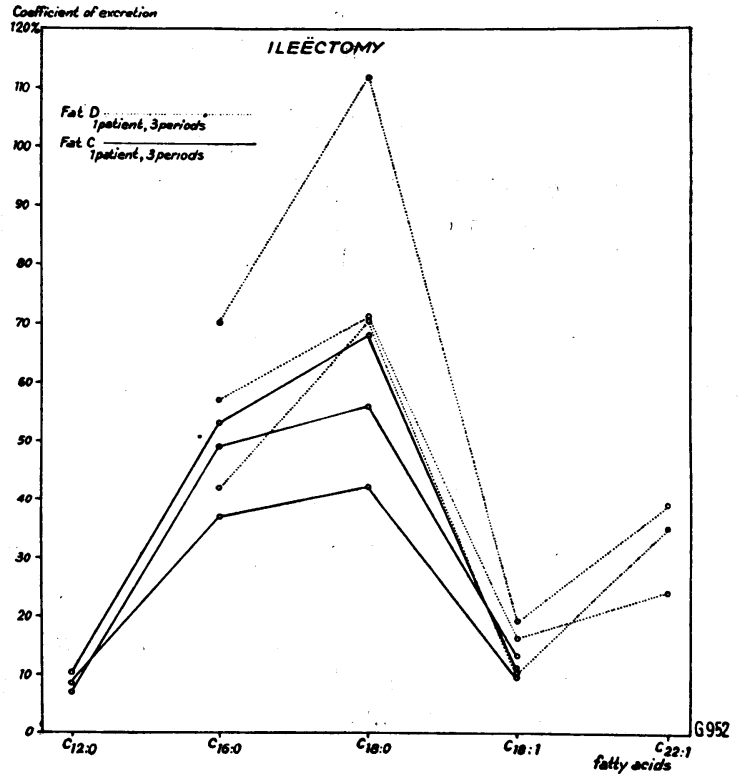

Fig. 7. Coefficients of excretion of SEVERAL Fatty ACIDS IN FATS FED TO A PATIENT WITH STEATORRHEA SECONDARY TO ILEECTOMY. Each series of points connected by a line represents one balance period.

B. Cystic fibrosis of the pancreas. Fat absorption studies were carried out in seven children with cystic fibrosis of the pancreas (Figures 4 and 5 ). It can be seen that the CEs increase as the molecular weight increases only for the lower molecular weight $n$-saturated fatty acids and that there are irregular differences between the CEs of the saturated and monoenoic acids of higher molecular weight. Here also there is more complete absorption of the polyenoic acids than of the more saturated homologs. Expressed in terms of their excretion indices, the low molecular weight

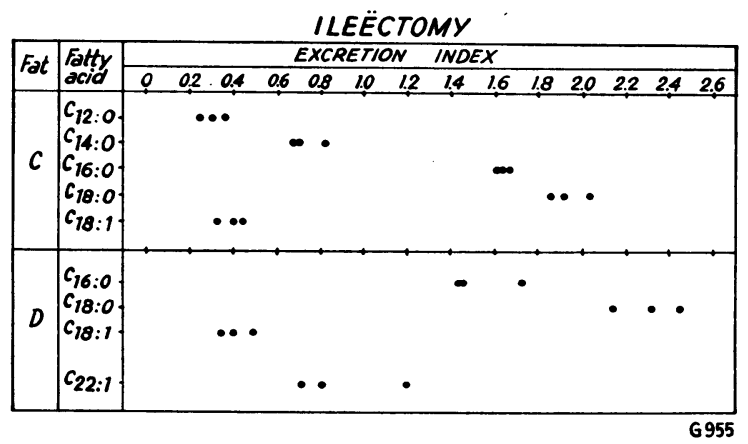

Fig. 8. EXCRETION INDICES OF VARIOUS FATTY ACIDS AFTER ADMINISTRATION OF DIFFERENT FATS TO A PATIENT WITH STEATORRHEA SECONDARY TO ILEECTOMY. 
and the unsaturated fatty acids fed to these patients are absorbed most completely. In this instance, however, the progressive increase in excretion index for the homologous series is not seen except for the lower molecular weight $n$-saturated acids.

C. Ileectomy. Fat mixtures $\mathrm{C}$ and $\mathrm{D}$ were fed to a girl who had developed steatorrhea after the resection of all of the ileum and part of the distal jejunum (Figures 7 and 8). The operation had been necessitated by bowel necrosis after volvulus. The CEs of the $n$-saturated homologs were found to increase with increasing molecular weight. Oleic acid was more completely absorbed than was the saturated 18-carbon acid. Erucic acid was less completely absorbed than the smaller monoenoic acids, and in this instance (fat $D$ ) behenic acid, the $n$-saturated 22-carbon fatty acid, was found in the fecal fat. The excretion indices showed the same progression which has already been seen in the studies on patients with celiac disease.

\section{DISCUSSION}

It is noteworthy that in some instances a coefficient of excretion greater than 100 was found. At least in part this is possibly the result of conversion of unsaturated into saturated acids by intestinal microorganisms or intramucosal enzyme systems. Hydrogenation was suggested by the observation in the patient with steatorrhea secondary to ileectomy that small amounts of behenic acid appeared in the fecal fat after she was fed a fat containing erucic acid. A partial conversion from erucic acid to behenic acid has previously been demonstrated in nontropical sprue (17). Such saturation could explain the finding in patients with cystic fibrosis of a CE for stearic acid greater than 100. Partial saturation is suggested in one of the patients with celiac disease (Figure 2) who excreted large quantities of oleic acid after ingesting a fat containing chiefly linoleic and linolenic acids (fat $F$ ).

The possible formation of hydroxystearic acid in the intestinal lumen should also be considered, since this would probably not be detected in these studies. This acid has been demonstrated in the feces of a patient with endemic sprue (18).

If any of these reductions occurred, the absorption of the unsaturated acids would be slightly less than we have indicated. Thus, although these conversions are of lesser magnitude, the data concerning the unsaturated acids must be interpreted with these reservations.

These possible conversions do not affect the observation of the progressive rise in the CEs of the saturated fatty acids. In steatorrhea the saturated fatty acids and polyunsaturated fatty acids of lower molecular weight are selectively absorbed from the mixture of partial glycerides and free fatty acids in the intestinal lumen, so that higher molecular weight saturated fatty acids, being less well absorbed, are recovered more completely in the lipids excreted in the stools. Such selective absorption has already been demonstrated in animal experiments $(1,19)$. In order for this selection to occur, there must be quite extensive intraintestinal hydrolysis, a fact previously determined $(11,20)$. As further evidence for the necessity of lipolysis, we have found in the patients with a basis for relatively incomplete hydrolysis (cystic fibrosis) that the differences between the excretion indices of the various fatty acids are less marked than in those patients with normal pancreatic function but abnormal or deficient mucosa. The absorption of fatty acids released by pancreatic lipase may be impeded if unsaturated or lowmolecular weight fatty acids are present in the intestine at the same time. This suggests competition in absorption of fatty acids. Competition, a phenomenon already known to exist in the absorption of amino acids and monosaccharides (21), is therefore an important factor in absorption in general.

The findings in these studies suggest that fatty acid absorption in patients with steatorrhea is determined by three factors: 1) Chain length; the absorption is found to decrease as the molecular weight rises. 2) Degree of saturation; fatty acids with one or more double bonds are absorbed to a greater degree than are their saturated counterparts; indeed, the $\mathrm{C}_{18}$ polyunsaturated acids are absorbed more completely than is oleic acid. 3) The composition of the dietary fat; the degree of absorption of any given fatty acid is greater if it is fed with less well absorbed fatty acids.

From these observations we conclude that patients with steatorrhea should be fed unsaturated fats. This is in accordance with our earlier findings in patients with celiac disease (22). 


\section{SUMMARY}

In children with steatorrhea due to celiac disease, cystic fibrosis, or ileectomy the extent of absorption of different fatty acids was studied by feeding fats of various fatty acid compositions. The differences between coefficients of excretion of different fatty acids suggested that there is a selective absorption which favors species of lower molecular weight; i.e., the lower the molecular weight, the greater the absorption. In addition we have found that a selection exists, which favors absorption of those acids with more double bonds. It is suggested that such a selective action is due to competition, and therefore absorption is a function of the fatty acid composition of the dietary fat. A given fatty acid is absorbed to a greater extent when it is fed in combination with fatty acids that are less well absorbed.

For such competition and selective absorption to occur, extensive hydrolysis of the dietary fat is required in the small intestine. When hydrolysis was less complete, as in those patients with diminished hydrolysis due to cystic fibrosis of the pancreas, the differences in absorption of the various fatty acids were less marked.

It is concluded that patients with steatorrhea may be benefited by ingesting fats composed of unsaturated fatty acids.

\section{ACKNOWLEDGMENT}

The authors acknowledge with gratitude the critical review of this manuscript by Dr. Marvin H. Sleisenger and Dr. Malcolm Peterson.

\section{REFERENCES}

1. Bloom, B., Chaikoff, I. L., and Reinhardt, W. O. Intestinal lymph as a pathway for transport of absorbed fatty acids of different chain lengths. Amer. J. Physiol. 1951, 166, 451.

2. Shiner, M. Coeliac disease: Histopathological findings in the small intestinal mucosa studied by a peroral biopsy technique. Gut 1960, 1, 48.

3. Bergström, S., Borgström, B., and Carlsten, A. On the mechanism of intestinal fat absorption in the cat. Acta physiol. scand. 1954, 32, 94.

4. Bernhard, K., and Bodus, $H$. Ueber stark fetthaltige Körperergüsse beim Menschen. Helv. physiol. pharmacol. Acta 1948, 6, 68.

5. Blomstrand, R., Thorn, N. A., and Ahrens, E. H., Jr. The absorption of fats, studied in a patient with chyluria. I. Clinical investigation. Amer. J. Med. 1958, 24, 958.

6. Blomstrand, R., and Ahrens, E. H., Jr. The absorption of fats studied in a patient with chyluria. II.
Palmitic and oleic acids. J. biol. Chem. 1958, 233, 321.

7. Fernandes, J., van de Kamer, J. H., and Weijers, H. A. The absorption of fats studied in a child with chylothorax. J. clin. Invest. 1955, 34, 1026.

8. Kiyasu, J. Y., Bloom, B., and Chaikoff, I. L. The portal transport of absorbed fatty acids. J. biol. Chem. 1952, 199, 415.

9. Blankenhorn, D. H., and Ahrens, E. H., Jr. Extraction, isolation, and identification of hydrolytic products of triglyceride digestion in man. J. biol. Chem. 1955, 212, 69.

10. Harris, R. S., Chamberlain, J. W., and Benedict, J. H. Digestion of neutral fats by human subjects. J. clin. Invest. 1955, 34, 685 .

11. Ahrens, E. H., Jr., and Borgström, B. Exchange of free fatty acids and glyceride fatty acids during fat digestion in the human intestine. J. biol. Chem. 1956, 219, 665 .

12. Blomstrand, R., Lindquist, B., and Paäbo, K. The intestinal absorption of carbon-labelled oleic and palmitic acid in the normal infant and in cystic fibrosis of the pancreas. Helv. paediat. Acta 1955, $10,640$.

13. Boldingh, J. Fatty acid analysis by partition chromatography. Rec. Trav. chim. Pays-Bas 1950, 69, 247.

14. van de Kamer, J. H., Pikaar, N. A., Bolssens-Frankena, A., Couvée-Ploeg, C., and van Ginkel, $L$. Quantitative determination of the different higher saturated fatty acids in fat from blood, chyle and faeces, by means of partition chromatography on rubber. Biochem. J. 1955, 61, 180.

15. Pikaar, N. A., and Nijhof, J. Microdetermination of the fatty acids in blood serum. Biochem. J. 1958, 70, 52.

16. Farquhar, J. W., Insull, W., Rosen, P., Stoffel, W., and Ahrens, E. H., Jr. The analysis of fatty acid mixtures by gas-liquid chromatography. Nutr. Rev. 1959, 17, no. 8, part II, suppl.

17. Sammons, H. G., Wigs, S. M., and Frazer, A. C. Studies on faecal fat. Proc. Int. Congress Gastroenterology. Leiden, The Netherlands, 1960, p. 617.

18. James, A. T., Webb, J. P. W., and Kellock, T. D. The occurrence of unusual fatty acids in faecal lipids from human beings with normal and abnormal fat absorption. Biochem. J. 1961, 78, 333.

19. Mattil, K. F., and Higgins, J. W. The relationship of glyceride structure to fat digestibility. I. Synthetic glycerides of stearic and oleic acids. J. Nutr. 1945, 29, 255.

20. Borgström, B. On the mechanism of pancreatic lipolysis of glycerides. Biochim. biophys. Acta 1954, 13, 491.

21. Quastel, J. H. Intestinal absorption of sugars and amino acids. Amer. J. clin. Nutr. 1960, 8, 137.

22. Weijers, H. A., and van de Kamer, J. H. Coeliac disease. III. Excretion of unsaturated and saturated fatty acids by patients with coeliac disease. Acta paediat. (Uppsala) 1953, 42, 97. 